\title{
El exilio como concepto político en la Carta a los españoles americamosde Juan Pablo Viseardo y Guzmán
} Exile as Political Concept in Juan Palblo Viscalrdo y
Guzman's Letter to the Spanish american people

\author{
Marie Elise Escalante \\ Universidad Nacional Mayor de San Marcos, Lima, Perú \\ Contacto: mescalantea@unmsm.edu.pe \\ https://orcid.org/0000-0001-6508-635X
}

\section{RESUMEN}

En la obra de Viscardo y Guzmán, el exilio deja de ser solo un dato biográfico o una experiencia vital y se convierte en una categoría conceptual para comprender la historia americana y la condición colonial de los españoles americanos. Como demostración de ello, Viscardo y Guzmán recuerda el exilio de numerosos nobles incas luego de la rebelión del último Inca de Vilcabamba, Tupac Amaru I y lo relaciona con la reciente expulsión de sus pares jesuitas de América. También considera que los conquistadores y Cristóbal Colón, quienes se exiliaron voluntariamente para servir al rey, no fueron recompensados por este $y$, por el contrario, fueron castigados sin razón alguna. Con esta reflexión acerca de la historia colonial americana, Viscardo y Guzmán sostiene que esta solo ha sido una sucesión de maltratos e injusticias por parte del Rey. Así, llega a la conclusión de que América es un lugar donde se atenta contra los derechos básicos de los americanos y donde ellos están a la merced de un soberano que posee un poder ilimitado. En otras palabras, América vive en un estado de excepción permanente. El exilio viene a ser ese síntoma o indicio que revela la condición de tiranía a la cual viven sometidos los españoles americanos durante todos los tres siglos de colonia. En este estudio, vamos a analizar las relaciones que Viscardo y Guzmán establece entre la noción de estado de excepción, la condición de sujetos sin derechos y la de los exiliados, así como el rol fundamental del soberano dentro de este estado de excepción propio de la condición colonial

Palabras clave: Exilio; Soberano; Estado de excepción; Homo sacer; Españoles americanos.

\section{ABSTRACT}

Exile is, in Viscardo Guzmán's works, not only a biographical fact but an important concept to understand Spanish American history and colonial condition. In his Letter, Viscardo y Guzmán gives some historical examples of the King's cruelty towards his colonial subjects, from the Andean nobles exiled after the rebellion of Tupac Amaru I, the last Inca from Vilcabamba, to the recent expulsion of his Jesuits brothers. He arrives at the conclusion that the Spanish Crown has only mistreated and unjustly punished the Spanish Americans in these two hundred years of colonial history. Viscardo y Guzmán's discourse shows that Spanish American's rights are not recognized by the Spanish crown and Spanish Americans live under the rule of a permanent state of exception. Exile is one of the most visible signs of the tyranny that Spanish Americans are subjected to during the two centuries of colonial history. In this text I study the relation between the figure of the sovereign and the state of exception in Viscardo y Guzmán's Letter and exile as one of the main conditions of colonial subjects, an exile not only in geographical but also historical terms. According to Viscardo y Guzmán, Americans are exiled from their own history. To understand the notion of sovereignty and state of exception I take into account classical authors such as Jean Bodin and Hobbes as well as contemporanean ones such as Carl Schmitt, Giorgio Agamben, and Walter Mignolo.

Keywords: Exile; Dovereign; State of exception; Homo Sacer; Spanish americans. 


\section{Introducción}

El exilio es una de las constantes en la historia latinoamericana desde tiempos coloniales; por ello, es importante analizar sus transformaciones y su dinámica a lo largo de los siglos. Al hacerlo, se puede ver la historia peruana y latinoamericana desde una perspectiva continental y transatlántica. Visto como un fenómeno político, el exilio ha tenido una importante influencia en la definición de las identidades nacionales y latinoamericanas. Según Luis Roniger (2007, p. 31), el exilio es uno de los principales medios de control y exclusión practicado por las élites políticas latinoamericanas para mantenerse en el poder. Ha sido usado a lo largo de la historia como un mecanismo de control y de exclusión para eliminar la disidencia política (Roniger y Sznajder, 2013).

Durante la colonia, el exilio recibía el nombre de "destierro" o "degredo" y recaía sobre individuos considerados como una amenaza al orden social. Fue reservado a los vagabundos, los soldados desertores, los criminales y ladrones. También era aplicado a rebeldes provenientes de las clases altas o élites de la sociedad. No solo las autoridades seculares tenían potestad de castigar con el exilio, sino también el Santo Oficio. Los condenados por este tribunal eran los herejes, los judaizantes, los blasfemos, los bígamos, los religiosos que rompían con sus votos de castidad, los que caían en prácticas supersticiosas, entre otros. Las penas de destierro podían ir acompañadas de otros castigos, como las galeras, la cárcel o la confiscación de bienes. En algunos casos, el destierro tenía funciones estratégicas, pues servía para poblar lugares lejanos, situados en los confines del imperio. Durante la colonia, el destierro o degredo tuvo un efecto social ejemplarizante y sirvió también como una muestra de poder de la clase dominante.

En las postrimerías de los tiempos coloniales se dio uno de los casos más remarcables de exilio con el destierro masivo de jesuitas del territorio europeo y americano en 1767. Carlos III, junto con otros soberanos de toda Europa, expulsó alrededor de cinco mil jesuitas de sus reinos. Los motivos de esta medida excepcional no fueron declarados por el rey, por lo que hubo un aura de misterio en esta acción. El "motín de Esquilache" en Madrid fue una de las principales causas que originaron la expulsión, ya que, de acuerdo con Pedro Rodríguez de Campomanes
- el fiscal a cargo de la pesquisa sobre el motín-, los jesuitas fueron instigadores de tal desorden y por ello recomendaba su expulsión del imperio (Bravo, 2007, p. 421). También fue importante, en el ámbito americano, la rebelión contra los corregidores en las reducciones de indios de Misiones, un territorio que estaba casi en completo control de los jesuitas (Mörner, 1966, p. 5). Sin embargo, en un análisis más detenido, el exilio masivo de los integrantes de la Compañía de Jesús se puede interpretar como una muestra de la supremacía del poder real sobre el poder religioso. Las consecuencias en América de la expulsión de los jesuitas lo demuestran: luego de ella, la corona procedió a reformar las otras órdenes religiosas y se embarcó en una extensa reforma universitaria. De tal forma, con esta expulsión, la corona consolidó su control sobre la Iglesia de sus colonias americanas y, aún más, ocupó espacios que antes no tenía, como el ámbito educativo, lo cual permitió un mayor control y vigilancia de la sociedad hispanoamericana, uno de los objetivos principales de las reformas borbónicas.

Todo el gran contingente de jesuitas exiliados fue enviado a Italia, donde se dedicaron a la enseñanza o a la investigación académica. Así, Italia llegó a ser, en el último cuarto del siglo XVIII, el centro más denso de todo el americanismo europeo (Batllori, 1966, p. 590). Fueron alrededor de cinco mil jesuitas españoles, la mayoría provenientes de las colonias americanas; estos debían residir en los tres Estados pontificios septentrionales: Bolonia, Ferrara y Rávena. Entre los jesuitas expulsados hubo un grupo de criollos que, con sus obras, exaltaron la identidad americana y se dedicaron a polemizar con sus pares europeos, como Raynal, De Paw y Buffon, quienes consideraban a los americanos, a sus pueblos y su naturaleza como inferiores. Las obras de jesuitas como Francisco Clavijero, Juan Ignacio Molina, Juan de Velasco, entre otros, contribuyeron a la construcción de la identidad criolla con sus reflexiones sobre los mitos, la naturaleza e historia americanas. No obstante, ninguno de ellos fue más allá de la apologética a la identidad americana ni se involucraron en una labor conspirativa contra la corona española, como Juan Pablo Viscardo y Guzmán Zea y Andía (1748-1798). La obra de este arequipeño de nacimiento es breve, pero su influencia dentro del proceso emancipador e independentista es insoslayable (Viscardo y Guzmán, 1988). Su obra más canónica, Carta dirigida a los españoles americanos, 
divulgada por Francisco de Miranda en 1791, fue importante para la emancipación americana. Viscardo y Guzmán no escribe como un solitario exiliado, sino como un representante o portavoz de toda la comunidad de jesuitas exiliados, especialmente de los 2154 jesuitas americanos. En su obra se dedicó a hacer análisis sobre la situación económica y social de América. Viscardo y Guzmán puede ser considerado como uno de los primeros pensadores liberales del Perú y de Latinoamérica, y, en este aspecto es, pues, un pionero que aún no ha sido reconocido del todo respecto a su sitial en la historia de las ideas políticas y económicas americanas.

$\mathrm{Su}$ construcción de la patria americana consiste en una reflexión crítica acerca de su presente colonial, una propuesta de reforma política y económica y, por último, la proyección de una utopía futura. La mirada negativa, casi luctuosa del presente viene atemperada por una mirada esperanzada en un futuro utópico, en el cual América será regida por los lineamientos del libre mercado y estará abocada a la prosperidad económica. A diferencia del jesuita mexicano Francisco Clavijero, autor de Historia antigua de México (1780), Viscardo y Guzmán no escribe acerca de las antigüedades de los indios, sino que se dedica de modo preferente a destacar la importancia de los criollos, quienes serían los miembros más importantes del continente americano, a los cuales los indios y otras castas están asociados y en algunos casos, subordinados. Viscardo y Guzmán va más allá de los pensadores que exaltaban la patria criolla, ya que llega a reconocer los derechos naturales de todos los individuos de la sociedad colonial, independientemente de su etnia o clase social. La Carta ha sido descrita como un documento inestable que, por un lado, argumenta la superioridad de los criollos en el liderazgo político de América y, por otro, hace suya la doctrina de los derechos humanos universales. Este es uno de los aciertos más importantes de la Carta y lo que constituye una innovación con respecto al resto de discursos criollistas de la época: "Lo que hacía la Carta algo tan efectivo era precisamente su combinación de los lamentos tradicionales del patriotismo criollo con la insistencia de la Ilustración en los derechos naturales" (Brading, 2011, p. 51).

Por el afán de denuncia de la Carta se puede establecer una similitud con la Brevísima relación de
Bartolomé de Las Casas, cuya estructura se basa en la enumeración de masacres, matanzas y abusos de los españoles hacia los indios. Pero a diferencia del texto lascasiano, Viscardo y Guzmán llega a cuestionar en el suyo la condición de súbdito español, la obediencia al rey y la lealtad al imperio español.

En el caso de la Carta de Viscardo y Guzmán propongo que el tema del exilio no solo es parte de su trayectoria vital, biográfica, sino que este se convierte en una herramienta conceptual para pensar la historia y la situación de los americanos sometidos al yugo colonial. El exilio también es importante para comprender la crítica al poder real del exjesuita arequipeño, sobre todo porque el exilio es una medida excepcional del rey, que muestra su poder absoluto, ilimitado y, por tanto, tiránico. A continuación trataré sobre la importancia del exilio en la narración y análisis de la historia colonial de la Carta, y en la siguiente sección profundizaré en la imagen del rey, para lo cual haré uso de los estudios de Schmitt (2015) y Agamben (1996, 1998, 2005) sobre la autoridad en política y el estado de excepción.

\section{La historia americana como una historia de exilio}

La Carta dirigida a los españoles americanos presenta la historia de América como una historia de exilio. Su denuncia de la subordinación o subalternidad del sujeto colonial se construye con esta narrativa de exilio. Con ello se puede decir que tiene una mirada histórica, al igual que la de otros jesuitas americanos exiliados, como Francisco de Clavijero. Pero su mirada sobre la historia difiere profundamente de la de ellos. Viscardo y Guzmán narra la historia de América como una historia de opresión y de tiranía. No mira al pasado prehispánico para exaltarlo, como lo hace el jesuita mexicano, sino que se concentra en los años coloniales, para denunciar los abusos del rey y de las autoridades virreinales.

La historia americana que narra Viscardo y Guzmán es una historia de exiliados y de trayectorias transatlánticas. Debido a ello, Pablo Macera (1999) sostiene que el pensamiento del exjesuita arequipeño no puede entenderse dentro de categorías nacionales o protonacionales, sino que su obra solo se puede comprender con categorías globales. Macera propone 
el término de "criollo colonial", entendiendo que no solo hubo criollos en el imperio español, sino que "todo imperio tiene colonias y es propenso a la aparición de sus respectivos coloniajes" (1999, p. 272). La Carta de Viscardo y Guzmán sería, así, una reflexión de la condición colonial por la cual se puede hacer comparaciones o aproximaciones con otras obras coloniales que no sean del ámbito peruano o latinoamericano. También es importante tomar en cuenta el contexto de su composición. Viscardo y Guzmán se hallaba en Gran Bretaña cuando escribió la Carta, y en esa época era financiado por el gobierno británico para conspirar contra la corona española. Entonces, los planes separatistas de Viscardo y Guzmán eran considerados como favorables para los británicos, porque tenían como objetivo arrebatarle a España su hegemonía política y económica en América. Visto desde este punto de vista, la Carta de Viscardo y Guzmán no solo es importante en la historia de la América española, sino también en el estudio de las relaciones imperiales entre España y Gran Bretaña de dicha época.

Viscardo y Guzmán inicia la Carta sosteniendo que los americanos deberían reconocer a América como su patria por encima de España. En su idea de patria, Viscardo y Guzmán incluye no solo la cuestión del territorio, sino también la de una historia común, los derechos naturales, dentro de los cuales se encuentran los derechos de propiedad y libre comercio. De esta manera, la idea de patria abarca lo territorial, lo histórico, lo económico y lo legal. La declaración de América como patria implica una toma de posesión, de dominio del territorio americano por parte de los criollos, desplazando así a los españoles que se han adjudicado el poder y dominio de América. Cito a Viscardo y Guzmán:

El Nuevo Mundo es nuestra patria, su historia es la nuestra, y en ella es que debemos examinar nuestra situación presente, para determinarnos por ella, a tomar el partido necesario a la conservación de nuestros derechos propios y de nuestros sucesores. (2004, p. 73)

Enseguida, el exjesuita peruano muestra que los primeros conquistadores son los primeros exiliados, ya que son los españoles los que dejan su patria para vivir en América. Pero en este territorio americano siguen manteniendo el apego y la lealtad a España, continúan siendo fieles súbditos del rey.

El español americano se configura como un sujeto que no pertenece del todo ni a América ni a España. Esta doble pertenencia lo condena a una liminalidad, lo cual le impide asentarse o establecerse definitivamente en América. Dicho de otro modo, para Viscardo y Guzmán la condición colonial es un estado de liminalidad o desarraigo perpetuo. Una de sus propuestas principales es, precisamente, superar esta situación de liminalidad o ambigüedad de los criollos. Esto pasa por romper con los vínculos afectivos y políticos con España y asumirse plenamente como americanos. Viscardo y Guzmán acusa a España de querer mantener a los americanos en esta situación liminal, dándose entonces la situación de que los americanos están desterrados de su propia patria e ignorantes de su propia historia: "La España nos destierra de todo el mundo antiguo, separándonos de una sociedad a la que estamos unidos con los lazos más estrechos" (2004, p. 75).

En su narración de la historia americana, Viscardo y Guzmán ve una continuidad sin fisuras entre el conquistador español y el español americano, algo que caracteriza a numerosos discursos criollos, como sostiene Bernard Lavalle (1993). Ser criollo implica, en el discurso de Viscardo y Guzmán, al igual que en la mayoría de discursos criollos de la época, tener intereses, apegos, lealtades al territorio americano más que una simple cuestión de nacimiento en la América hispánica. Uno de los puntos principales de su Carta es que este apego y lealtad a España que siempre han tenido los criollos y conquistadores nunca ha sido reconocido por la corona española. Para Viscardo y Guzmán, la historia americana es una sucesión de ingratitudes, injusticias, servidumbre y desolación, porque el rey, su corte y el virrey han violado durante todos estos cientos de años de orden colonial los derechos de los criollos. Cuando hace una enumeración de los hechos históricos relevantes para su argumentación, todos ellos están relacionados con el exilio, ya que es en este suceso en que se descubre en su real dimensión la crueldad y la tiranía del rey. El exilio es la prueba máxima de todas las tiranías que han sufrido los americanos de España: 
Si corremos nuestra desventurada patria de un cabo al otro, hallaremos dondequiera la misma desolación, una avaricia tan desmesurada como insaciable $[\ldots]$. Consultamos nuestro análisis de tres siglos y allí veremos la ingratitud y la injusticia de la corte de España, su infidelidad en cumplir sus contratos. Primero con el gran Colón y después con los otros conquistadores que le dieron el imperio del Nuevo Mundo, bajo condiciones solemnemente estipuladas. (Viscardo y Guzmán, 2004, p. 79)

Viscardo y Guzmán señala algunos núcleos problemáticos de la historia americana hasta el punto de configurarla como una sucesión de crisis causadas por el exilio de sujetos de España a América o viceversa. El exjesuita peruano ve la historia americana estrechamente vinculada a la historia española, lo cual le da a su obra una perspectiva transatlántica bastante marcada. En su análisis de la historia española, Viscardo y Guzmán establece que el poder absoluto de sus reyes es causante de la actual postración y decadencia de España. Este poder sin límites, como hemos visto, también explica la tragedia que vive la América hispana desde su origen.

La Carta de Viscardo y Guzmán resalta hechos paradigmáticos que sirven como ejemplo o modelo de lo que ha sucedido a lo largo de los tres siglos de colonia. Los eventos históricos a los que hace alusión son principalmente tres: el descubrimiento de América por Cristóbal Colón, la rebelión de Tupac Amaru I y el exilio de los jesuitas. La mención a Colón es significativa porque muestra que en el momento inaugural de la conquista y colonia se da un quiebre o violación del contrato o acuerdo de los reyes con Colón. La conquista comienza con este, se diría, pecado original de la violación de un contrato, ya que luego de Colón, la corona comete injusticias e ingratitudes análogas con los demás conquistadores. En el caso de Colón $\mathrm{y}$ el resto de conquistadores, su expatriacion o exilio ha sido voluntario para hacer un servicio al rey, pero Viscardo y Guzmán sostiene que no han sido recompensados por ello. Después de recordar a Colón, nuestro autor evoca a Tupac Amaru I y los nobles incas que fueron castigados cruelmente por el virrey Toledo por rebelarse. Para la narración de tal hecho cita al Inca Garcilaso de la Vega y agrega que estos nobles incas fueron desterrados luego de su revuelta. Los pasajes que cita de la Historia general del Perú son especialmente cargados de patetismo, ya que incluyen la exhortación de una madre a su hijo, un noble inca que fue parte de la rebelión de Tupac Amaru I para que sea fiel a sus compañeros de lucha y no los traicione. Luego de la extensa cita de Garcilaso, Viscardo y Guzmán comenta:

Esta exhortación magnánima, proferida con toda la vehemencia de que aquella madre era capaz, hizo la más grande impresión sobre el espíritu del virrey, y le apartó de su designio de hacer morir aquellos desdichados. Sin embargo, no fueron absueltos, sino que se les condenó a una muerte más lenta, desterrarlos a diversas partes del Nuevo Mundo. Algunos fueron también enviados a España. (2004, p. 80)

La rebelión de Tupac Amaru I es una rebelión india, con lo cual sería la contraparte a la mención de Colón, ya que el trato de Colón es un modelo del trato que han recibido los conquistadores e hijos de conquistadores. La rebelión de Tupac Amaru, por otro lado, muestra también la tiranía del rey contra los nobles indios. Viscardo y Guzmán describe con dramatismo el castigo que reciben los nobles indios de parte de las autoridades españolas del cruel virrey Toledo. A continuación, Viscardo y Guzmán establece una relación entre los nobles indios ajusticiados y el exilio de los jesuitas, del cual él es una de las víctimas. La descripción que hace del exilio de los jesuitas es mucho más virulenta y apasionada:

El Virrey, aquel monstruo sanguinario, pareció entonces el autor de todas las injusticias, pero desengañémonos, acerca de los sentimientos de la Corte, si creemos que ella no participaba de aquellos excesos; ella se ha deleitado en nuestros días en renovarla en toda la América, arrancándoles un número mayor de sus hijos, sin procurar disfrazar siquiera su inhumanidad: estos han sido deportados hasta en Italia.

Después de haberlos botado de un país, que no es de su dominación, y renunciándolos como vasallos, la Corte de España, por una contradicción y un refinamiento inaudito de crueldades, con un furor que solo puede inspirar a los tiranos el derecho de perseguirlos y oprimirlos continuamente. La muerte ha librado 
ya, a la mayor parte de estos desterrados, de las miserias que han acompañado hasta el sepulcro. Los otros arrastran una vida infortunada... (2004, p. 81)

Para el exjesuita peruano, el exilio implica perder la condición de vasallos del rey y, por ende, perder su protección. Con esto se abre la posibilidad de ejercer crueldades sobre ellos, como la persecución y la represión continua. Según Viscardo y Guzmán, el exilio revela el despotismo y la tiranía del gobierno español. Cada caso de exilio es recordado por él como una muestra evidente de la crueldad del régimen colonial, que se esconde bajo la máscara de justicia.

Vemos, además, las connotaciones del destierro para Viscardo y Guzmán: la muerte, la existencia miserable, la vida llena de infortunio. Hay una relación directa entre exilio y tiranía: para nuestro autor, solo los regímenes tiránicos exilian a sus miembros y esto equivale, para ellos, a una pena de muerte. La arbitrariedad con la cual el rey despojó a toda una generación de jesuitas de sus derechos y propiedades muestra este poder ilimitado del rey, por un lado, y también la total vulnerabilidad de los jesuitas que ante una orden real lo pierden todo, algunos hasta la vida:

La conservación de los derechos naturales y, sobre todo, de la libertad y seguridad de las personas y haciendas, es incontestablemente la piedra fundamental de toda sociedad humana [...] es manifiesto que cinco mil ciudadanos, que hasta entonces la opinión pública no tenía razón para sospecha de ningún delito, han sido despojados por el gobierno de todos sus derechos sin ninguna acusación, sin ninguna forma de justicia y del modo más arbitrario. El gobierno ha violado solemnemente la seguridad pública. (2004, p. 85)

La primera alusión al exilio jesuita sirve como una muestra de la tiranía real dentro de su narración de hechos históricos coloniales. En la segunda mención, Viscardo y Guzmán se sirve del ejemplo de los jesuitas para sostener que, en este caso, se han violado todos sus derechos naturales, los cuales son la base de la sociedad. Esto significa que, en América, los derechos naturales de sus súbditos no se reconocen ni se respetan.
Puede decirse que la Carta nos da un catálogo de casos de exilio colonial o destierro. Todos ellos sirvieron para expulsar a sujetos considerados rebeldes y tuvieron como propósito la pacificación del reino. Sin embargo, como hemos observado, en el caso específico de los jesuitas expulsos no hubo rebelión que justifique la pena del exilio. Por esta violación de los derechos naturales de sus súbditos, el rey pierde su condición humana y se convierte a los ojos de Viscardo y Guzmán en un monstruo sanguinario. Por ello, luego de mostrar la tiranía que ejerce la corona española sobre sus súbditos americanos, manifestada de modo ejemplar y extremo en el caso de los jesuitas, Viscardo y Guzmán invita a renunciar al ridículo "sistema de unión e igualdad" entre España y América, ya que esta igualdad es falsa, se trata de un contrato social nulo.

Viscardo y Guzmán se sirve de un argumento geográfico para dar sustento a su pedido de emancipación de España, ya que señala la gran distancia geográfica entre la Península Ibérica y América. Según el exjesuita, esta distancia geográfica puede verse como una oportunidad para emanciparse y dejar de mirar con apego a España y a su rey. Lo que también propone Viscardo y Guzmán en esta Carta es una inversión de la relación política y geográfica entre España y América: ya no será España el centro ni el rey el soberano, sino América y los americanos, quienes eran la periferia en el régimen colonial. Esto lo hace basándose en Montesquieu, quien sostiene que América, por su riqueza y sus recursos vale más que España. Así, la idea de emancipar América, para Viscardo y Guzmán, implica superar la colonialidad, lo cual no solo supone adoptar el liberalismo económico y político, sino también una emancipación mental o ideológica.

\section{Una reflexión sobre el poder real y la tiranía}

La Carta de Viscardo y Guzmán tiene reminiscencias a las cartas de relación que los conquistadores escribieron al rey de España con propósitos varios: elogiarlo, dar a conocer sus proezas o infortunios, aconsejar, persuadir, denunciar atropellos de funcionarios reales o virreinales, entre otros. Sin embargo, hay una diferencia fundamental: Viscardo y Guzmán no envía su carta al rey, sino a los que considera deberían ser los legítimos soberanos, los 
españoles americanos. Esto no quiere decir que el rey - el receptor desplazado de la Carta - pierda importancia en su obra. Si bien Viscardo y Guzmán no se dirige al rey, toda su carta y la descripción de los hechos históricos que relata: exilio, pena de muerte, contratos rotos, todos son hechos en los cuales la mano del monarca es determinante.

La reflexión acerca del exilio presente en la Carta se relaciona directamente con una disquisición acerca del poder del rey. El exjesuita criollo remarca que el responsable de su exilio y de esta historia de tiranía en América es el rey. El exilio revela el exceso de poder real y es una muestra manifiesta de la violación de los derechos primordiales de sus súbditos. La Carta resulta, pues, un alegato contra el poder excepcional del rey, que viola los derechos de sus súbditos y los reduce a una condición semejante a los animales.

La idea de contrato social que plantea Viscardo y Guzmán está influenciada por los planteamientos de Jean Jacques Rousseau y su Contrato Social, pero también por autores del Renacimiento, como los jesuitas Francisco Suárez y Juan de Mariana (Scarano, 2013). Suárez desarrolló una de las doctrinas más influyentes acerca de la ley natural en su obra De Legibus (1612). En ella sostiene que las leyes naturales vienen de Dios y tienen como principal objetivo el bien común. Suárez plantea el origen contractual del poder, es decir, es necesario un consenso entre el rey y los gobernados para que el poder del monarca sea legítimo. Esto implica que el poder no viene directamente de Dios al rey, como sostenían los que creían en el derecho divino de los reyes, sino que es producto de este acuerdo entre los soberanos y sus súbditos. En su obra Defensio Fidei (1613) propone la desobediencia civil en caso de que el rey dicte leyes injustas, incluso admite la posibilidad del tiranicidio (cfr. Caro y Saldivia, 2013). Por su parte, Juan de Mariana desarrolla en su obra De rege et regis institutione (1599), un tratado dedicado a la educación de los príncipes o espejos de príncipes, la legitimidad del tiranicidio (cfr. Merle, 2014). Las universidades jesuitas de España y América tenían cátedras dedicadas a la enseñanza de las doctrinas de Suárez, las cuales fueron cerradas por Carlos III luego de la expulsión de los jesuitas de España y América.
Sin embargo, para comprender mejor la Carta conviene también analizar las teorías sobre el poder político que sostienen lo opuesto a la postura contractual y legalista de Viscardo y Guzmán, ya que su texto tiene un evidente tono polémico hacia un rey que no está condicionado o determinado por la ley o por un contrato social, sino uno que se erige por encima de cualquier convención o regla. Las reflexiones que han hecho filósofos como Carl Schmitt y, en especial, Giorgio Agamben acerca del poder soberano y del estado de excepción son de mucha utilidad cuando se analiza los reclamos y acusaciones de Viscardo y Guzmán al rey y al régimen colonial en su Carta.

La figura del rey, con poder ilimitado y excepcional, es un planteamiento más acorde a una noción barroca del poder real, que surge durante los siglos XVI y XVII con la consolidación de las grandes monarquías europeas. Los filósofos Jean Bodin y Thomas Hobbes fueron dos de los principales pensadores que justificaron la soberanía del poder real. Hobbes en su Leviatán fundamenta la preeminencia del poder real como una garantía para el orden y la convivencia pacífica de los súbditos. Por su parte, Bodin sostuvo que el soberano estaba sujeto a la ley, pero que, en ciertas circunstancias excepcionales, no está sometido a ella. Así, el poder real para el filósofo francés es una alternancia entre un poder sujeto a las leyes y uno que, durante las situaciones de emergencia, prescinde de ellas. Bodin enumera algunos casos en los cuales rige esta excepcionalidad del poder: la declaración de guerra o de paz, el nombramiento de funcionarios, el otorgamiento del perdón, entre otros. En el siglo XVIII, por el contrario, la corriente de pensamiento contractualista y legalista del poder fue la que tuvo mayor predominio. Sin embargo, este planteamiento tiene una concepción formalista del poder y no podía explicar la figura política del soberano y del estado de excepción o de emergencia.

Fue Schmitt quien retomó la reflexión de Hobbes y Bodin sobre el estado de excepción y del soberano en su obra Teología política. Para Schmitt, el soberano es aquel que tiene el poder de decisión en el estado de emergencia o excepción. Su concepto del poder es situacional y coyuntural antes que basado en leyes o axiomas. Schmitt sostuvo que era necesario analizar los estados de emergencia o de excepción, pues ellos no son simples anomalías, sino que son los que 
revelan la esencia del poder. El estado de excepción se conforma por situaciones no codificadas, no existentes ni previstas por el orden legal, que ponen en peligro la existencia misma del Estado. El soberano tiene la potestad de decidir durante los momentos de extrema emergencia. Esto demuestra que el monarca pertenece al orden legal, pero al mismo tiempo lo trasciende, porque toma decisiones cuando las leyes o el orden constitucional necesita ser suspendido. Según el filósofo alemán, el estado de excepción revela que la decisión del soberano es la base del orden jurídico. Por su parte, Agamben sostiene que el soberano es la figura en la cual se basa gran parte de la política de Occidente, desde la antigua Grecia hasta los tiempos contemporáneos. El soberano tiene el poder de decidir e instaurar el estado de excepción. Esto implica que, así como es el garante de las leyes, también puede suspenderlas. Según Agamben, el estado de excepción es lo que Hobbes en su obra llama estado natural. El estado de excepción es un estado primordial, anterior o un estado donde la noción de polis no se encuentra vigente.

Esta descripción del estado de excepción como una vuelta al estado natural está acorde con lo que Viscardo y Guzmán nos presenta en su obra. Por ejemplo, cuando hace un símil entre el poder del rey y un mar tempestuoso que inunda la tierra: "La autoridad real, semejante al mar cuando sale de sus márgenes, inundó toda la monarquía, y la voluntad del rey, y de sus ministros, se hizo la ley universal" (2004, p. 84). Viscardo y Guzmán compara el poder real en América con una fuerza de la naturaleza que es una amenaza permanente para los hombres. A diferencia de Hobbes, quien ve el poder real como un baluarte para que los ciudadanos no se destruyan entre ellos, Viscardo y Guzmán, debido a su orientación legalista y contractualista, tiene una apreciación negativa del poder del soberano, ya que lo considera como una amenaza a la libertad y a los derechos de sus súbditos. Para Viscardo y Guzmán, la autoridad del rey está contenida y limitada por contratos, acuerdos, leyes dados, en algunos casos, desde la antigüedad. Cuando el rey no respeta estas leyes y actúa siguiendo solo su voluntad, pierde su legitimidad. Se da, entonces, una antinomia entre las leyes y la voluntad del rey. Este debe ceder, invariablemente en favor de la ley.

Así, Viscardo y Guzmán le quita al rey la capacidad de decisión fuera del marco de las leyes y es considerado más como un funcionario que hace cumplir la ley antes que en un sujeto del cual emana el poder y la autoridad. Esta mirada legalista del poder real explica por qué en la Carta hay una desacralización y una deslegitimación de la figura del monarca. En ella, el rey aparece ya sea como un tirano o, en otros casos, no es considerado como la única instancia de poder soberano. Es notorio que Viscardo y Guzmán hace una distinción entre la historia antigua y la más reciente. En su obra, el rey aparece como el principal detentador del poder, cuando se refiere a la historia española antigua. Sin embargo, cuando se refiere a acontecimientos de la historia colonial, menciona también a la corte real, como si el poder del rey ya no estuviera concentrado solo en su persona, sino en todo un conjunto de personas. Por ejemplo, en un pasaje de su Carta, el intelectual criollo atribuye a la Corte de España, en su conjunto, el propósito de mantener a sus súbditos americanos en el desconocimiento de sus derechos naturales para así mantener su tiranía:

La pretensión de la Corte de España a una ciega obediencia a sus leyes arbitrarias, está fundada principalmente sobre la ignorancia que procura alimentar y entretener, sobre todo acerca de los derechos inalienables del hombre, y de los deberes indispensables de todo gobierno. (2004, p. 82)

En otros casos, Viscardo y Guzmán habla simplemente del gobierno, sin nombrar a ningún actor específico. Se puede apreciar en ello la burocratización y la despersonalización del poder real. Sin embargo, es interesante distinguir que, en la Carta, la figura del virrey tiene aún esa aura de poder ilimitado y personal, a la cual se le puede adjudicar la responsabilidad de la tiranía ejercida en América. Por eso, el exjesuita se refiere al virrey Toledo con epítetos tan virulentos como "hipócrita feroz" y trata de "monstruo sanguinario" al virrey Amat, quien ordenó la expulsión de los jesuitas.

Frente al soberano que dicta y decide el estado de excepción tenemos a todos aquellos que padecen las consecuencias de sus actos. El análisis que hace Viscardo y Guzmán de la situación de los súbditos del rey en las colonias americanas es semejante a lo que Agamben describe en Homo sacer (1998). El filósofo italiano utilizó el término de "Homo sacer" 
para denominar a los que viven en una situación de emergencia o de excepcionalidad dictada por el soberano. Según Agamben, el Homo sacer es un sujeto que está fuera del ámbito de las leyes y ha perdido todos sus derechos, por lo cual puede ser asesinado, maltratado por cualquiera, sin ser defendido por nadie; en otras palabras, es un individuo que se halla en un estado completo de vulnerabilidad.

Viscardo y Guzmán sostiene que América está bajo el signo de la tiranía porque el rey, en la práctica, viola continuamente los derechos de sus súbditos. Así, le dedica especial atención a denunciar al rey por la violación de los derechos de libertad y de propiedad de los americanos. El maltrato del gobierno es mayor que el que los americanos imaginan, porque no solo es una cuestión de cargos públicos que les son negados, sino de la libertad, la propiedad y, en algunos casos, como es de los exiliados, de la vida que les es arrebatada. En la Carta, Viscardo y Guzmán acusa al rey de hacer leyes arbitrarias que no redundan en el bien común, sino que destruyen la prosperidad de los americanos. Esto implica que el soberano solo cuida sus propios intereses o fines sin importarle el bienestar de sus gobernados. En otras palabras, el rey o la Corte de España disponen de sus súbditos americanos como lo haría con sus esclavos. En tal sentido, América es un territorio de esclavos, no de hombres libres:

[...] toda ley que se opone al bien universal de aquellos, para quienes está hecha, es un acto de tiranía, y que el exigir su observancia es forzar a la esclavitud, que una ley que se dirigiese a destruir directamente las bases de la prosperidad de un pueblo, sería una monstruosidad superior a toda expresión; es evidente también que un pueblo, a quien se despojase de la libertad personal y de la disposición de sus bienes [...] se hallaría en un estado de esclavitud mayor que el que puede imponer un enemigo en la embriaguez de la victoria. (Viscardo y Guzmán, 2004, p. 75)

Más adelante, Viscardo y Guzmán sostiene que la condición de los españoles americanos ya no es solo la de esclavos, sino la de animales. El exjesuita relaciona la condición colonial con la de una manada de animales, remarcando la facilidad con la que el gobierno español no cumple sus compromisos ni respeta sus derechos. El rey tiene la posibilidad de sacrificarlos, despojarlos de su libertad y confiscar sus bienes:
Mas si el gobierno se cree superior a estos deberes para con la nación; ¿qué diferencia hace pues entre ella y una manada de animales, que un simple capricho del propietario puede despojar, enajenar y sacrificar? [...] y si sucede en las enfermedades políticas de un estado, como en las enfermedades humanas, que nunca son más peligrosas que cuando el paciente se muestra insensible al exceso del mal que le consume. (2004, p. 85)

Viscardo y Guzmán equipara al rey con un vulgar salteador de caminos debido a su sistemático afán por adueñarse de los bienes que corresponden a sus súbditos americanos. No solo esto, nuestro autor va más allá: le quita cualquier justificación o legitimidad al sistema colonial al considerar que este se basa, desde sus inicios, en la expoliación y el robo. Vuelve a denunciar que, en el transcurso de los siglos, el poder del rey se ha hecho cada vez más arbitrario y tiránico. Esto implica una denuncia a las medidas económicas y políticas implementadas por Carlos III conocidas como las reformas borbónicas:

Ya hemos visto la ingratitud, la injusticia y la tiranía, con que el gobierno español nos acaba desde la fundación de nuestras colonias, esto es cuando estaba él mismo muy lejos del poder absoluto y arbitrario a que ha llegado después. $\mathrm{Al}$ presente que no conoce otras reglas que su voluntad, y que está habituado a considerar nuestra propiedad como un bien que le pertenece [...]. Esta lógica es la de los salteadores de caminos, que justifica la usurpación de los bienes ajenos, con la utilidad que de ella resulta al usurpador. (Viscardo y Guzmán, 2004, p. 86)

América es el espacio en el cual el rey se revela como un soberano con poder ilimitado, cuya voluntad se pone por encima de los derechos de los ciudadanos. Por ello se configura como un espacio sometido a un estado de excepción permanente, donde las leyes se violan y se transgreden. América está en la frontera, en una zona de absoluta indeterminación entre la anomia y la ley. En tal sentido, es inevitable considerar el espacio colonial dentro las reflexiones acerca de los regímenes de excepción:

[...] el espacio por excelencia donde el poder soberano se constituye bajo el paradigma de la excepción es el "espacio colonial": invención 
profundamente marcada por la exceptio (jerárquica) del poder imperial [...]

No sería exagerado afirmar que el lugar por excelencia de la biopolítica moderna es el espacio colonial. (De Oto y Quintana, 2010, pp. 50, 52)

Walter Mignolo (2008) sostiene que el orden colonial es una máquina productora de sujetos desechables, y que la historia de América colonial posee una de las muestras más tempranas de lo que Agamben llama Homo sacer o la "nuda vida". En el caso específico del orden colonial, las vidas se convierten en desechables al ser consideradas como mercancía.

Existe también una cercanía entre el Homo sacer y el exiliado, ya que la figura del exiliado es una muestra de que la condición de súbdito o ciudadano no es intrínseca a todos los hombres. El exiliado es, precisamente, aquel que está despojado de una relación con un Estado o Nación. El exilio, así, pone en crisis las convenciones políticas y jurídicas al uso. No solo esto, el exilio se halla en una zona de indiferencia entre exclusión e inclusión dentro la sociedad y de las leyes. "El exilio no es, pues, una relación jurídicopolítica marginal, sino la figura que la vida humana adopta en el estado de excepción, es la figura de la vida en su inmediata y originaria relación con el poder soberano" (Agamben, 1996, p. 61).

El exiliado tiene insospechadas relaciones con el soberano, ya que ambos se hallan en el espacio de la excepción, el lugar en donde las leyes y las normas pierden su validez. En otras palabras, tanto el exiliado como el monarca están por encima o más allá de la ley. Por ello, la situación de exilio le da a Viscardo y Guzmán una invaluable posibilidad de reflexionar acerca del lugar de excepción que él ocupa como exiliado y también señalar la excepcionalidad del rey dentro del orden colonial. El exilio de los jesuitas es, en la Carta, este caso excepcional que revela el mal funcionamiento de todo el sistema colonial. Así, el exilio muestra los mecanismos de la realeza y desnuda la indefensión de todos los súbditos americanos ante el rey. Para el exjesuita peruano, el exilio le sirve para tomar conciencia de la situación de excepción de todos los americanos. Por ello, el exilio es, también, para él, una instancia de reflexión intelectual y filosófica.
Viscardo y Guzmán enfatiza que la emancipación de los americanos depende de la decisión de los pueblos americanos; es decir, la instancia de la decisión que - según Schmitt y Agamben - define al soberano, ya no residiría en el rey de España sino en los americanos. Esto puede suponer, de modo inquietante, que se pasa de un estado de excepción, regido por el rey, a uno tutelado por el pueblo, ya que la llamada a la rebelión muestra los límites de su propio planteamiento legalista y contractual. No obstante, para que los americanos se conviertan en soberanos se deben dar cuenta de su desventajosa, penosa situación. Viscardo y Guzmán constata que la mayoría de ellos vive ignorante de estar sometidos a una tiranía, por ello sufren lo que él llama una "enfermedad política". La Carta tendría como objetivo curarlos de esta enfermedad, haciéndolos conscientes de su condición subhumana y exhortándolos a remediarla, rebelándose. Así, Viscardo y Guzmán se presenta en la Carta como líder y maestro, un antecedente de los letrados del siglo XIX que guiaron los destinos de sus naciones, recientemente independizadas.

\section{Conclusión: la patria americana de Viscardo y Guzmán}

Durante la colonia, la noción de patria podía aludir a una ciudad o incluso un pueblo con el cual se tenía un apego especial. Posteriormente, en el siglo XVIII, la patria tuvo un alcance continental, como consecuencia de las reformas borbónicas. Por otro lado, la nación tenía un componente étnico y cultural; así, durante la colonia, existía la nación de indios y la nación de criollos, y durante gran parte de ella hubo un ordenamiento rígido que separó a los indios de los españoles y criollos, en cuestiones administrativas. Esto llegó a su fin en el siglo XVIII, cuando se implementó una decidida política de homogeneización y centralismo. Pero la distinción entre indios y otras castas sigue en pie, aunque no sea del mismo modo que en los dos primeros siglos de colonización. La Carta, al dirigirse preferentemente a los españoles americanos, todavía funciona siguiendo la lógica de esta separación de castas. Sin embargo, en su narración de la historia colonial, nos presenta una historia común donde las distintas etnias coloniales comparten un pasado y un destino común, ya que establece una relación entre los padecimientos de 
Cristóbal Colón, el destierro de los nobles indios, descritos por el Inca Garcilaso, y los infortunios de los jesuitas criollos.

La utopía que Viscardo y Guzmán bosquejó en las últimas líneas de su Carta y de modo más extenso en su obra posterior es una utopía americana, basada en los lineamientos del liberalismo económico. La exaltación de América se da en la proyección de un futuro utópico, en el cual el nuevo continente va a lograr prosperidad con sus actividades productivas y su comercio libre, dirigido a todos los rincones de la tierra. La América futura de Viscardo y Guzmán reunirá las extremidades de la tierra y acogerá a todos los hombres de distintos lugares que desean vivir en ella.
Desde la Antigüedad griega, el exilio tuvo un estatus ambiguo; los filósofos debatían si era un castigo o si, por el contrario, era un refugio. En la Carta de Viscardo y Guzmán vemos que el exilio se configura como un castigo cercano a la muerte; sin embargo, al final de la Carta, cuando nuestro autor proyecta el futuro de prosperidad de América, el exilio puede llegar ser un refugio para todos los extranjeros que deciden emigrar a este continente. Así, el destino de América sigue relacionado con el exilio, aunque bajo el signo inverso: en vez de enviar a sus hijos al exilio, América va a ser un refugio de todos los extranjeros - exiliados o no-, ya que encuentran en ella prosperidad económica, libertad y concordia.

\section{Referencias bibliográficas}

Agamben, G. (1996). Política del exilio. Archipiélago, Cuadernos de crítica de la cultura, 26-27, 41-61.

Agamben, G. (1998). Homo sacer. Sovereign Power and Bare Life. Stanford University Press.

Agamben, G. (2005). State of exception. The University of Chicago Press.

Batllori, Miguel, S. J. (1966). La cultura hispano-italiana de los jesuitas expulsos: españoles, hispanoamericanos, filipinos: 1767-1814. Gredos.

Bodin, J. (1973). Los seis libros de la República. Madrid: Editorial Aguilar.

Brading, D. (2011). Profecía y Patria en la Historia del Perú. Fondo Editorial del Congreso del Perú.

Bravo, G. (2007). Las consecuencias económicas de la expulsión de los jesuitas de las provincias de Chile y Perú. En M. Marzal y L. Bacigalupo, Los Jesuitas y la modernidad en Iberoamérica (421-445). Instituto Francés de Estudios Andinos.

Caro, F. y Saldivia, Z. (2013). Francisco Suárez y el impacto de su teoría sobre la potestad divina y monarquía en América. Cuadernos del Pensamiento Latinoamericano, 18, 1-14. https://bit.ly/3mcFPPC

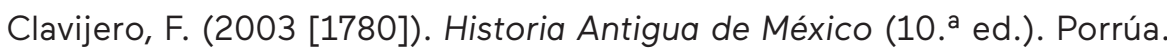

De Oto, A. y Quintana, M. (2010). Biopolítica y colonialidad. Una lectura crítica de Homo Sacer. Tabula Rasa, 12, 47-72. https://doi.org/10.25058/20112742.384.

Hobbes, T. (2005). Leviatán. Fondo de Cultura Económica.

Las Casas, B. de. (2006 [1552]). Brevísima relación de la destrucción de las Indias. Edición de José Miguel Martínez Torrejón. Alicante: Biblioteca Virtual Cervantes. http://www.cervantesvirtual.com/nd/ark:/59851/bmcjm259.

Lavalle, B. (1993). Las promesas ambiguas. Criollismo Colonial en los Andes. Pontificia Universidad Católica del Perú.

Macera, P. (1999). Viscardo y los criollismos coloniales. En VV. AA., Juan Pablo Viscardo y Guzmán (1748-1798). El Hombre y su tiempo II (269-272). Fondo Editorial del Congreso del Perú.

Merle, A. (2014). El De Rege de Juan de Mariana (1599) y la cuestión del tiranicidio: ¿un discurso de ruptura?. Criticón, 120-121, 89-102. https://doi.org/10.4000/ criticon.779. 
Mignolo, W. (2008). La opción de-colonial: Desprendimiento y apertura. Un manifiesto y un caso. Tabula Rasa, 8, 243-281. https://doi.org/10.25058/20112742.331.

Mörner, M. (1966). Los motivos de la expulsión de los jesuitas del Imperio Español. Historia Mexicana. El Colegio de México, 16(1), 1-14. https://historiamexicana. colmex.mx/index.php/RHM/article/view/1070/961.

Roniger, L. (2007). Antecedentes coloniales del exilio político y su proyección en el siglo XIX. Estudios Interdisciplinarios de América Latina y el Caribe, 18(2), 3152. http://eial.tau.ac.il/index.php/eial/article/view/573.

Roniger, L. Sznajder, M. (2013). La política del destierro y el exilio en América Latina. Fondo de Cultura Económica.

Scarano, M. (2013). La carta a los españoles americanos, de Juan Pablo Viscardo. Aportes para el estudio del siglo XVIII hispanoamericano. América sin nombre, 18, 149-161. https://doi.org/10.14198/AMESN2013.18.13.

Schmitt, C. (2015). Political theology. University of Chicago Press.

Viscardo y Guzmán, J. P. (1988). Obra completa. Biblioteca Clásicos del Perú, Banco de Crédito del Perú.

Viscardo y Guzmán, J. P. (2004). Carta dirigida a los españoles americanos. Fondo de Cultura Económica. 